\title{
Rehabilitation of the Komati River Bridge B1604
}

\author{
Johnnie Strydom ${ }^{1, *}$, Etienne du Plessis ${ }^{2}$, and Lourens Pieters $^{3}$ \\ ${ }^{1}$ WSP Africa, Johannesburg, South Africa \\ ${ }^{2}$ SMEC South Africa, Pretoria, South Africa \\ ${ }^{3}$ DSC Zendon cc, MBR, Johannesburg, South Africa
}

\begin{abstract}
In this paper, the retrofitting and rehabilitation of the Komati River Bridge, Bridge B1604 on the N4 in Mpumalanga, South Africa, is presented. The bridge consists of 17 simply supported spans, 20 metres in length, with a post-tensioned beam and slab deck. The deck is supported on steel bearings, and the abutments are of the spill through reinforced concrete type. The wall type piers are founded on shallow rock with pad footings. The bridge was constructed in 1940, and in 1998 the deck was widened on both sides with larger pre-cast, post-tensioned beams. SMEC South Africa under a Trans African Toll Concessions (TRAC) appointment inspected the bridge in 2014 as part of South African National Roads Agency's (SANRAL) routine bridge inspections. It was found that the old beams had extensive bending cracks. The cracks were mainly caused by locked in loads due to the jamming of the steel bearings. The rehabilitation design was completed by SMEC South Africa and was implemented by DSC Zendon cc with TRAC as the client in 2017. The repairs included the replacement of 272 steel bearings with elastomeric bearings, crack injection and carbon fibre strengthening of 68 deck beams. DSC Zendon cc utilised mobile platforms to access the soffit of the deck. Hanging platforms were used to minimise the impact on the Komati River and its crocodiles.
\end{abstract}

\section{Introduction}

\subsection{Scope of works}

SMEC South Africa was appointed by the Trans Africa Toll Concession (TRAC) to undertake the detailed inspection, rehabilitation design and construction supervision of the Komati River Bridge, Bridge B1604. The bridge is situated on the N4 Section 8 at $\mathrm{km} 67.0$ and is an important river crossing for freight traveling between South Africa and Mozambique. A locality plan of the bridge is provided in Fig 1. The bridge was originally inspected as part of scheduled South African National Roads Agency (SANRAL) 5-yearly bridge inspections. An aerial photo of the bridge is provided in Fig 2. SMEC South Africa conducted a detailed inspection of the bridge, completed the rehabilitation design, and compiled the tender documentation for the repair items on the bridge. DSC Zendon cc completed the rehabilitation works.

Rehabilitation works required on the bridge included:

- Clearing the bridge of vegetation and debris

- Repair of spalling on parapets

- Sealing of cracks in deck and parapets
- Strengthening of the deck (inner beams only)

- Replacement of asphaltic joints

- Replacement of steel bearings with elastomeric bearings

- Protective coating to piers and columns

- Replacement of deck scuppers

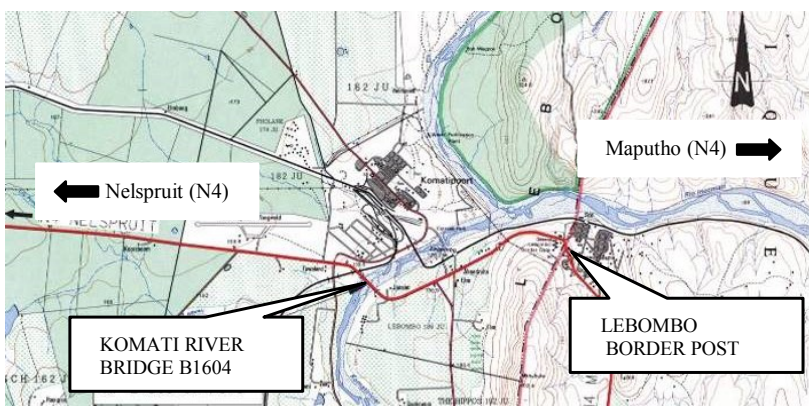

Fig 1: Locality plan of the Komati River Bridge B1604.

\footnotetext{
${ }^{*}$ Corresponding author: johnnie.strydom@wsp.com
} 


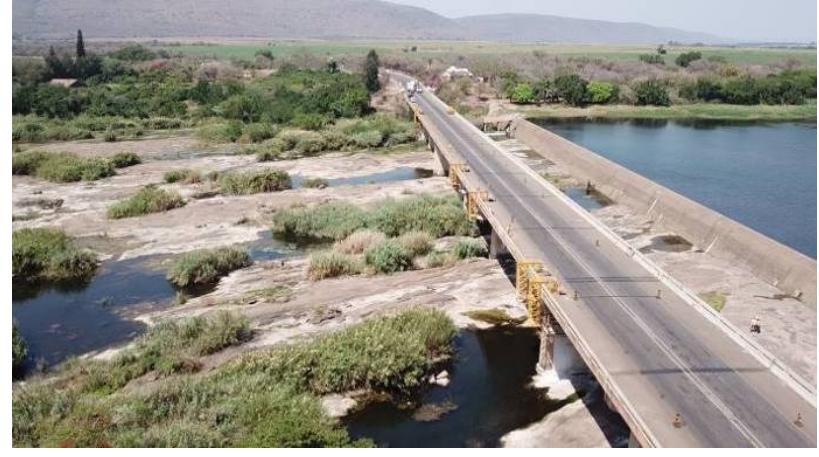

Fig 2: Aerial photo of the Komati River Bridge B1604.

\subsection{Background of the project}

Bridge B1604 provides access to the Lebombo border post, over the Komati River. The bridge has 17 spans (including two back spans at the abutments) and a total length of $327 \mathrm{~m}$. Each of 17 the spans has four 'old' beams and two new outer beams constructed in 1998 . The bridge has a pre-stressed precast beam and slab type deck, supported on wall type piers by means of steel bearings. The repair work was only required for the 'old beams' ( 68 beams in total). The bridge abutments are of the spill through type with reinforced concrete walls.

The parapets are of the F-shape ( $475 \mathrm{~mm}$ wide) type with cast in-situ end blocks. The bridge has asphalt plug type joints at the pier and abutment supports. The substructure is founded on shallow rock with pad footings. The deck is $12.4 \mathrm{~m}$ wide consisting of $2 \times 3.7 \mathrm{~m}$ lanes and $2 \times 2.5 \mathrm{~m}$ shoulders. A deck cross-section is provided in Fig 3.

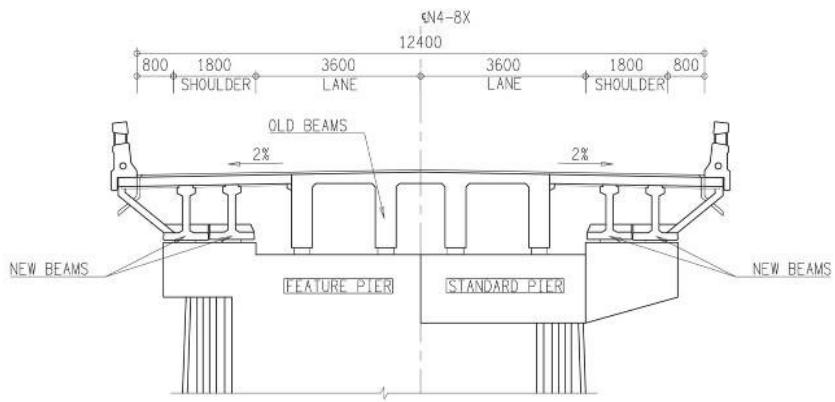

Fig 3: Deck cross-section - Komati River Bridge.

\subsection{History of the bridge}

The bridge was constructed in 1940 to provide a river crossing over the Komati River to the Lebombo Border post between South Africa and Mozambique. The bridge was subsequently widened in 1998 on both sides with larger pre-cast, post-tensioned beams to accommodate a $12.4 \mathrm{~m}$ wide road cross-section.

\section{Defects on the bridge}

A number of defects were identified during the SANRAL routine inspection in 2014. The main defects included locked bearings, shear cracks and bending cracks in the deck beams.
The shear and bending cracks were believed to have been caused by locked in thermal loading caused by seized bearings. Photos of the shear and bending cracks are shown in Fig 4 and Fig 5.

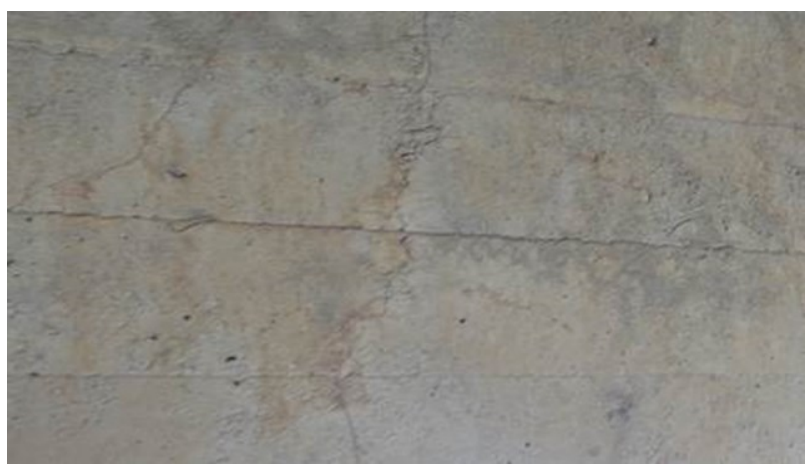

Fig 4: Shear cracks in the inner deck beams close to the supports of the Komati River Bridge B1604.

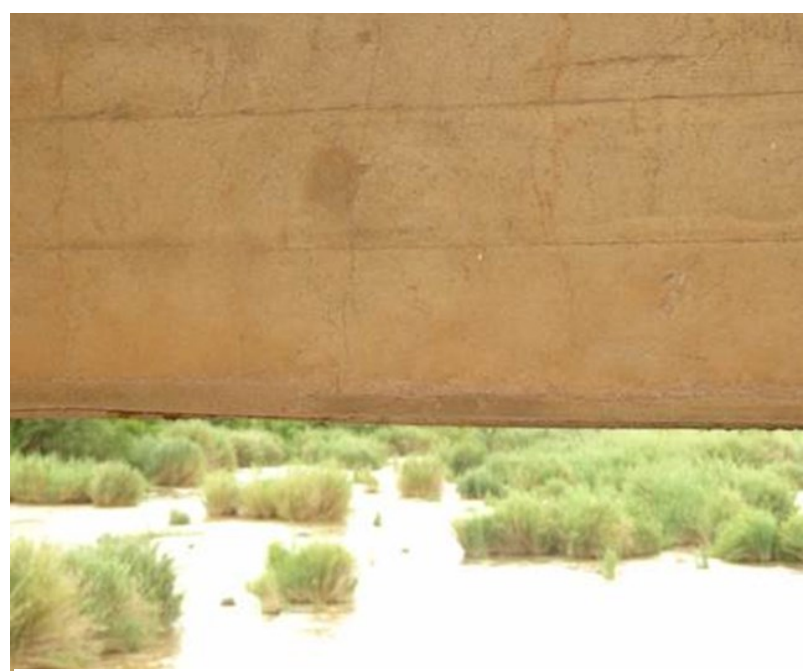

Fig 5: Bending cracks at mid-span of the inner deck beams of the Komati River Bridge B1604.

\section{Rehabilitation Design}

The detailed inspection was conducted on the bridge by using an Under Bridge Inspection Unit (UBIU). A photo of the UBIU is provided in Fig 6. The UBIU allowed the inspectors to inspect the bearings and the deck beams.

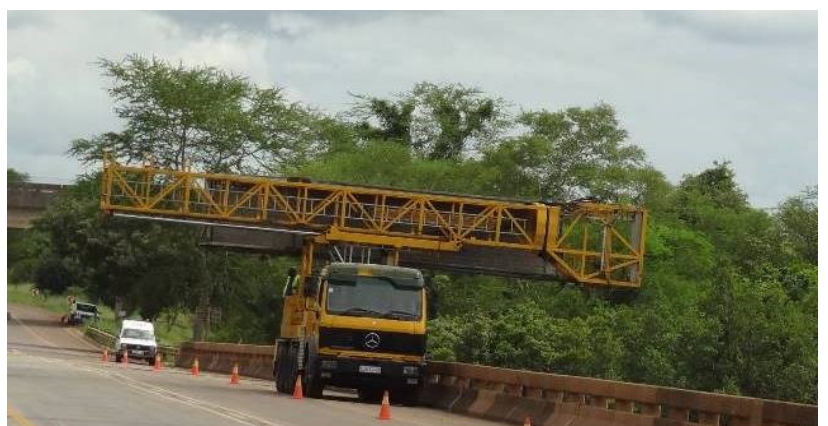

Fig 6: The Under Bridge Inspection Unit (UBIU) used for the detailed inspection of the Komati River Bridge B1604. 
After the detailed assessment, the rehabilitation works required were identified. The rehabilitation design was conducted in accordance with the following applicable codes and standards:

- Code of Practice for the Design of Highway Bridges and Culverts in South Africa - TMH 7 Parts 1 \& 2. (As amended in 1988).

- Code of Practice for the Design of Highway Bridges and Culverts in South Africa - TMH 7 Part 3.

- Code of Procedure for the Planning and Design of Highway and Road Structures in South Africa February 2002.

- Design loads: NA, NB 36 and NC 30 x 5 x 40 as per the codes above.

- BS 5400 - Steel, concrete and composite Bridges.

- Eurocode 2 (1991)

- Fib Bulletin 14 - Externally bonded FRP reinforcement for RC structures.

The rehabilitation design of the bridge consisted of the following key items: (i) replacement of the steel bearings; (ii) external strengthening of the inner deck beams; (iii) replacement of the Thorma joints; (iv) crack injection and spalling repair of the beams; (v) protective coating on bridge elements.

\subsection{Replacement of the steel bearings}

The bearings were locked mainly due to weathering. The seized bearings locked thermal loading into the deck and had to be serviced or replaced. The cost of servicing the existing steel bearings in comparison with the cost of replacing them with elastomeric bearings was considered. It was found to be more cost effective to replace the bearings with new elastomeric bearings in order to allow for thermal movement. The locked steel bearings are shown in Fig 7.

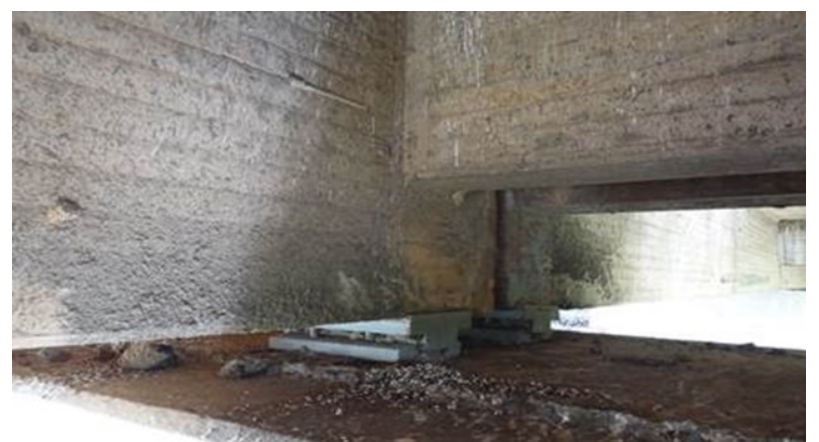

Fig 7: Locked steel bearings supporting the beam and slab deck of the Komati River Bridge B1604.

The new elastomeric bearings were designed using BS5400 and specified using COLTO as the project specification. Each of the deck spans had to be jacked to replace the steel bearings. The jacking height was limited to $15 \mathrm{~mm}$ to minimise the effect on the subsequent spans. The bridge joints had to be replaced and could therefore be damaged during the jacking operation. It was specified that no jacking could take place under live load conditions.

\subsection{External strengthening of the inner deck beams}

The inner beams had to be strengthened to prevent future cracking. For the strengthening of the beams, both steel plates and carbon fibre solutions were considered. Carbon fibre was chosen as it was easier to install and provided a more cost effective solution for this particular bridge.

Limit state design was used to calculate the carbon fibre required. This was done by calculating the additional material needed to resist the moment and shear force in the deck. The design included a verification of both the serviceability limit state (SLS) and the ultimate limit state (ULS). The deboning mechanism that may occur was considered. Deboning is best described as the peeling of the carbon fibre sheets from the concrete surface. This occurs when a crack propagates along the carbon fibre/concrete interface. The anchor length was calculated to prevent deboning from occurring in the flexural zone. In the shear zone the carbon fibre would be anchored above the centroid to prevent deboning.

Carbon fibre strips was specified for the flexural zone and carbon fibre cloth was specified for the shear zone to resist the bending moment and shear force respectively. The shear and flexural zones are indicated in Fig 8.

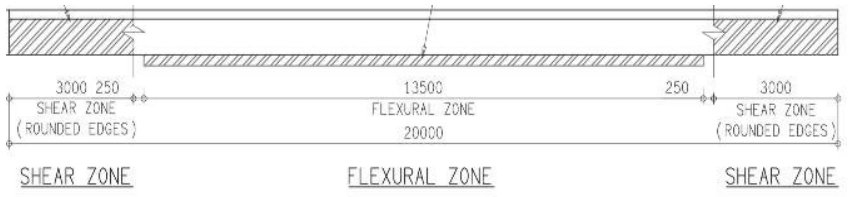

Fig 8: Shear and flexural zones.

\subsection{Replacement of the Thorma joints}

The Thorma joints had to be replaced as they were leaking and nearing the end of their service life. It was calculated that new Thorma joints $(500 \times 100 \mathrm{~mm})$ would be able to accommodate the thermal movement of the deck. Very little movement due to creep and shrinkage is expected as the bridge is more than 10 years old. It was specified that the now joints be SA Agrément approved and carry a 10 year guarantee.

\subsection{Crack injection and spalling repair}

The cracks present in the beams had to be sealed by means of crack injection before the external strengthening could commence. A reputable crack sealing epoxy and a cementitious grout was specified for crack injection and spalling repair respectively. 


\subsection{Protective coating of bridge elements}

It was specified that the pier foundations be coated with a protective coating if the water level permits, as it showed signs of soft water attack. Significant spalling was present on the parapets mainly due to minimal cover to the reinforcement. Protective coating was specified to prevent water ingress.

The protective coating specified was able to allow air and moisture to escape but would prevent the ingress of chlorides and water.

\section{Rehabilitation of Bridge B1604}

The rehabilitation process took place over a period of 9 months and was completed by DSC Zendon cc. The bridge had to remain open during the construction period. The bridge was only closed for few minutes during each jacking operation.

Prior to the repair work, the contractor had to ensure that the work area was free of obstructions as this would pose a safety risk. All working areas had to be barricaded off and notices and signs needed to be in place to alert workers as well as the general public.

Traffic accommodation had to be in place at all times to ensure safe access to the working area. The contractor had to ensure that the area was of acceptable standard to work (e.g. labourers sufficiently protected from passing traffic). All individuals on site had to wear personal protective equipment (PPE) that was clearly visible to passing vehicles. As part of the Department of Labour's requirements, the contractor had to obtain a work permit and clearly communicate the permit conditions to the workforce.

\subsection{Concrete Repair}

Concrete to be repaired was clearly marked out for the repair team. The affected concrete sections was square cut back to a sound substrate and to remove all of the badly patched areas as indicated in Fig 9. This was done using electric breakers and hand tools. All loose rubble and stones were transported by wheelbarrow and loaded onto a vehicle and removed from the site.

ABE Durarep FR was used as repair mortar. This product was applied in accordance with the manufacturer's specification to the area using a trowel, taking care not to entrap any air.

\subsection{Crack Injection}

Sikadur 52 was used for crack injection. All cracks that were injected had to be cleaned by hand with the use of steel wire brushes. Six $\mathrm{mm}$ holes were drilled into the cracks to a depth of $20 \mathrm{~mm}$. A five $\mathrm{mm}$ diameter copper pipe used to inject the epoxy into the crack was bonded to the concrete with Sikadur 31 epoxy paste. The crack was closed between the pipes with an epoxy paste and allowed to cure for 24 hours. The Sikadur 52 was then pumped into the crack by means of a pressure pump. The epoxy was pumped from the bottom pipe allowing the epoxy to fill the crack until the epoxy oozed out. This epoxy was allowed to cure for 24 hours before the protruding copper pipes and epoxy paste was removed from the surface by means of grinding. A sealed crack is shown in Fig 10.

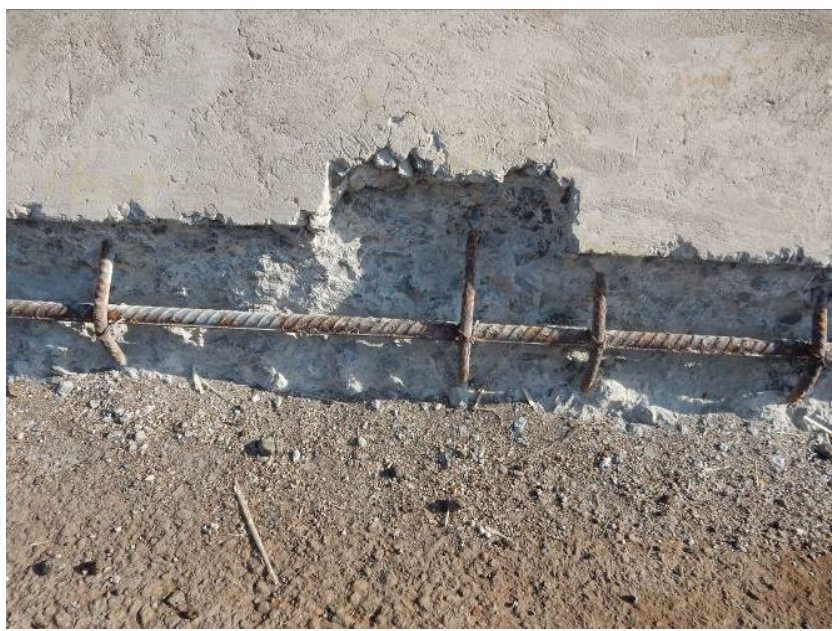

Fig 9: Concrete repair of spalling in the parapets.

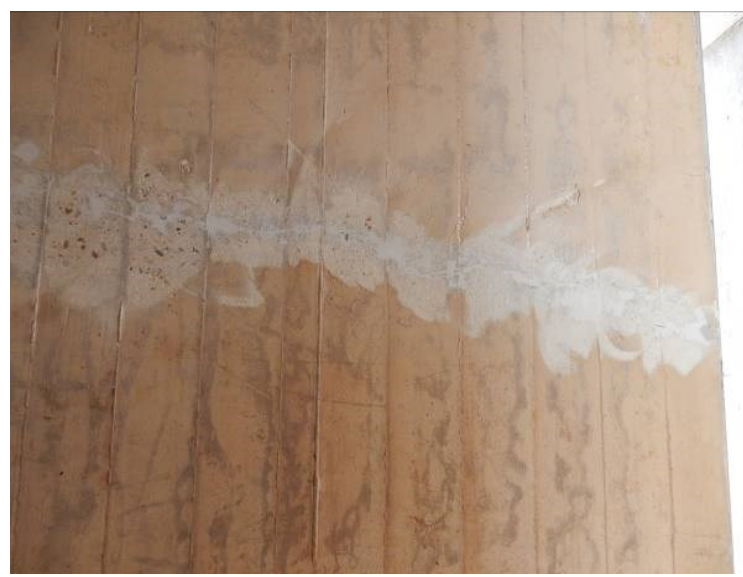

Fig 10: Crack injection of the inner beams.

\subsection{Methodology for carbon fibre strips (Bending)}

Sikadur 30 was used in conjunction with the composite carbon fibre strip. The carbon fibre strips were cut to the correct sizes as specified. All areas that had to be strengthened were inspected for damaged areas and repaired during the concrete preparation stage. Any unevenness or protrusions were grinded flush in the concrete preparation stage. The purpose of the concrete preparation stage was to remove any laitance from the surface of the concrete by means of grinding and to provide a clean and sound substrate to apply the carbon fibre strips.

The dust from the concrete surface was cleaned with a block brush or vacuum cleaner. All areas had to be marked out to determine the exact position for application of the required strips. Sikadur 30 epoxy adhesive was applied onto the carbon fibre strips by means of a scraper or application tool and installed onto 
the beams as per the drawings. A roller was used to press epoxy out at the sides of the strips and cleaned as shown in Fig 11. The epoxy was allowed to cure for 24 hours.

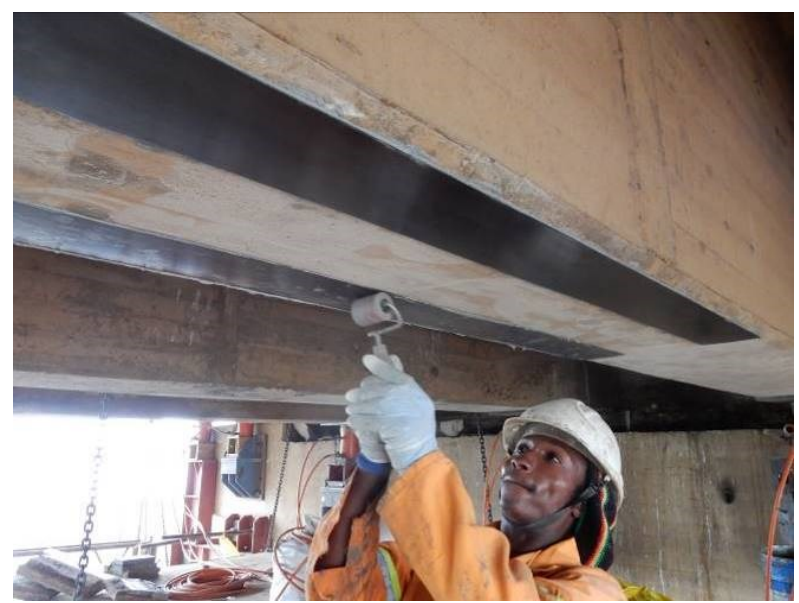

Fig 11: Installation of carbon fibre strips in the bending zone.

\subsection{Methodology for carbon fibre cloth (Shear Zone)}

The product Sikadur 330 was used together with composite carbon fibre cloth. All the areas that were strengthened were cleaned by means of grinding. All laitance and uneven concrete was removed and the edges rounded before applying the composite carbon fibre cloth.

All areas were marked out to determine the exact position for application of the carbon fibre cloth. A primer coat of Sikadur 330 was applied onto the clean concrete surface within the marked out areas. The carbon fibre cloth was applied onto the wet epoxy adhesive and the surface of the cloth was rolled with a ribbed roller. This was to ensure that all trapped air or bubbles were removed from the layered material and that the resin was pushed through the cloth. A second coat of epoxy adhesive was applied to cover the cloth evenly to ensure complete wet out of the carbon fibre cloth as shown in Fig 12.

After a 24 hour curing period, a visual inspection was conducted for any possible blow holes that may have occurred during the curing period. These holes were closed with Sikadur 330.

\subsection{Protective Coating}

All areas that were coated had to be cleaned by means of water jetting. Once the surface was clean and dry, protective coating could be applied to achieve a homogenous finish and colour. The coating was applied by means of a brush. Two coat applications in two different directions were applied. Abe's Silocoat was used as protective coating. The first coat was from left to right and the second coat was from top to bottom of the structure.

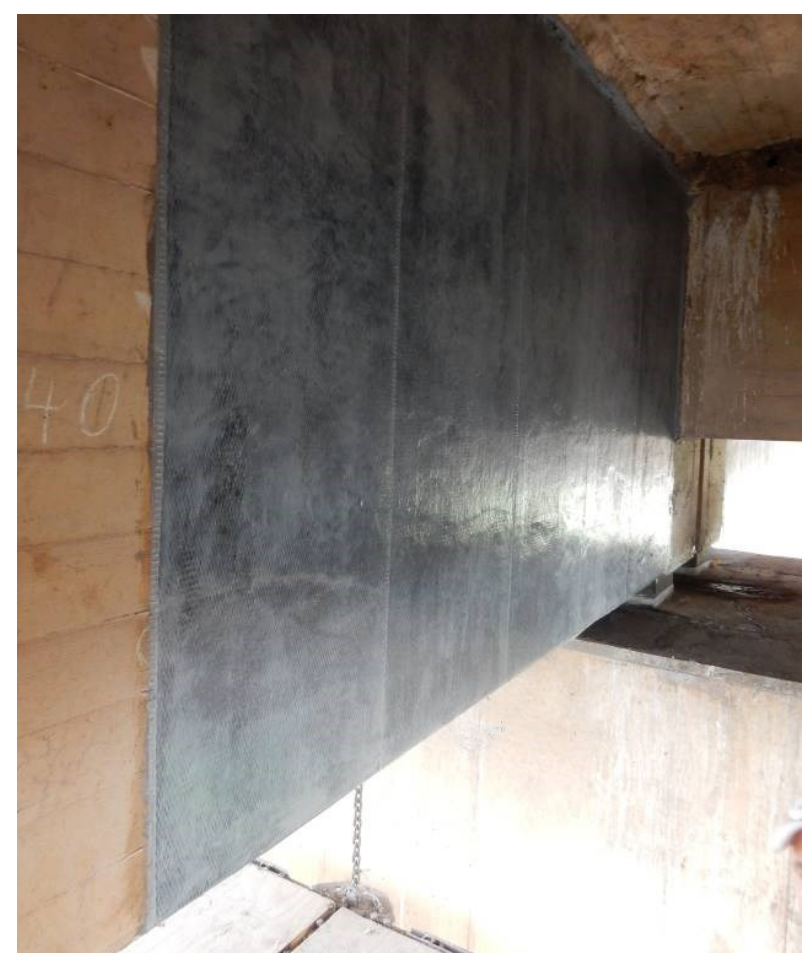

Fig 12: Installation of carbon fibre wrapping in the shear zone.

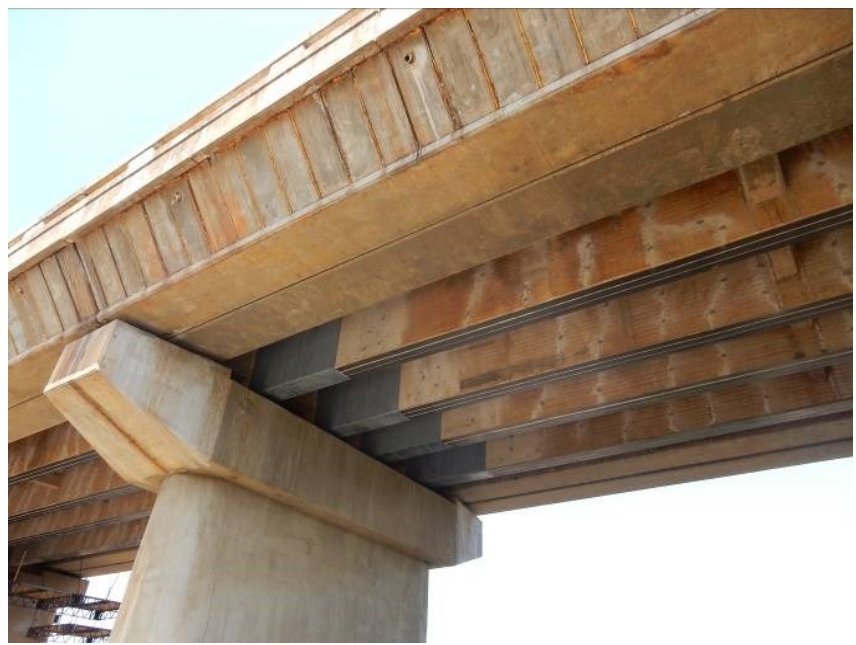

Fig 13: Elevation after the installation of carbon fibre.

\subsection{Thorma Joint Installation}

For the Thorma joint installation the operator had to cut the asphalt to the required depth on either side of the old joint using the concrete saw.

Paving breakers was used to remove asphalt and chip concrete down to the required depth to form the recess. A chisel was used to scrabble the deck to form an even base on both sides. A compressor and blowing out pipe was used to remove all loose material from the recess as shown in Fig 14. 


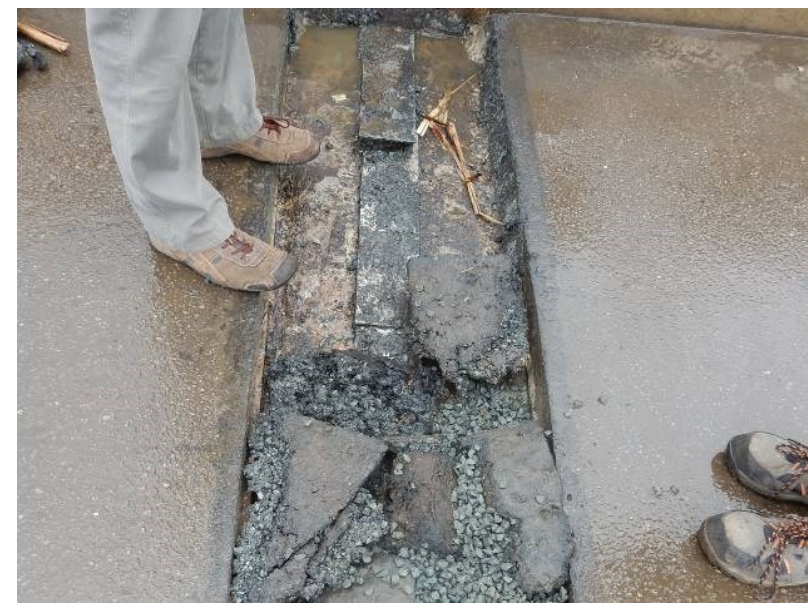

Fig 14: An existing Thorma joint cut for replacement.

The new Thorma joint was installed in accordance with the SA Agrément specification and sufficiently cooled before opening to traffic.

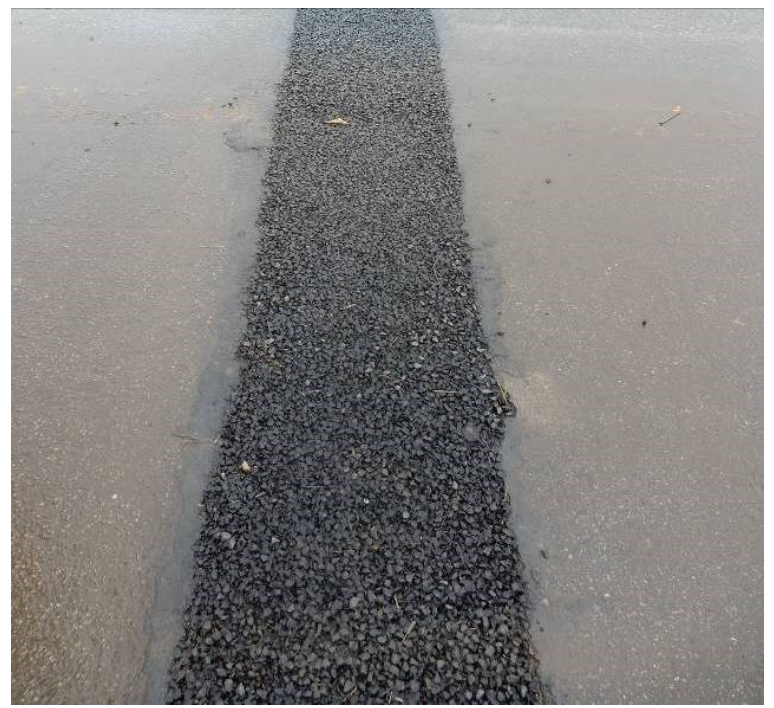

Fig 15: New Thorma joint before the seal coat was applied.

\subsection{Temporary Access Platforms}

The access system used consisted of a modular platform design, suspended from the deck soffit by chains. The suspended access system was designed with a factor of safety of four. The platforms ensured that scaffolding from the river bed was not required. This mitigated the risk of flooding damage to the form work and provided a safer alternative to the workers.

This access arrangement provided a $14,64 \mathrm{~m} \times 16,5 \mathrm{~m}$ working platform which was sufficient to cover the underside of each bridge span. In total, six sets of these platforms were used for the bridge rehabilitation. Photo's of the access platform is provided in Fig 16 and 17.

Holes were drilled to install stainless steel eye bolts in the bridge deck with Hilti epoxy (10 HVU Capsules) at pre-determined positions. Hoisting chains were attached through the eye bolts for the first platform on each span. The first platforms was erected below the bridge deck with the aid of an under bridge access unit/bogie as shown in Fig 18. The hanging cables were secured onto the platform at four fixing points on the platform.

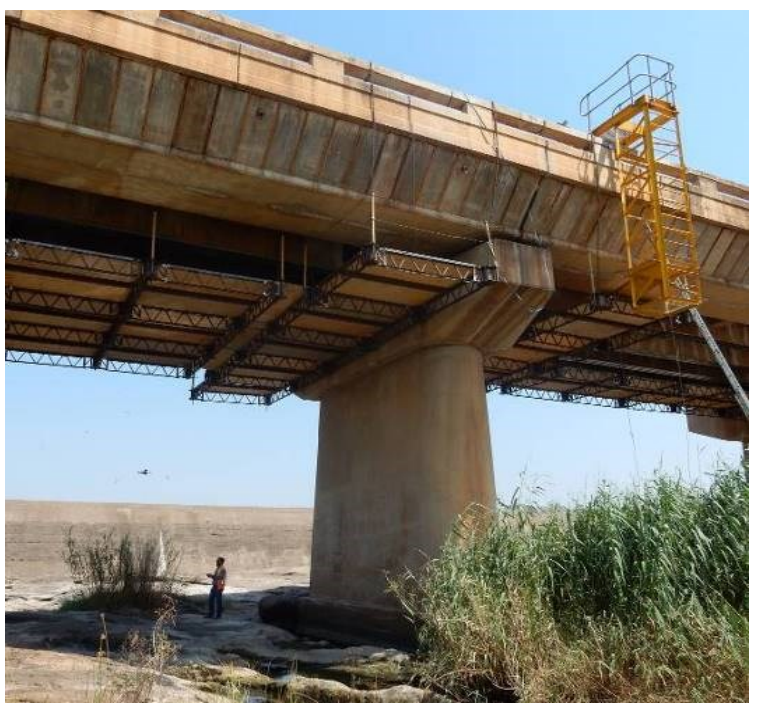

Fig 16: Temporary access platforms used on the Komati River Bridge B1604.

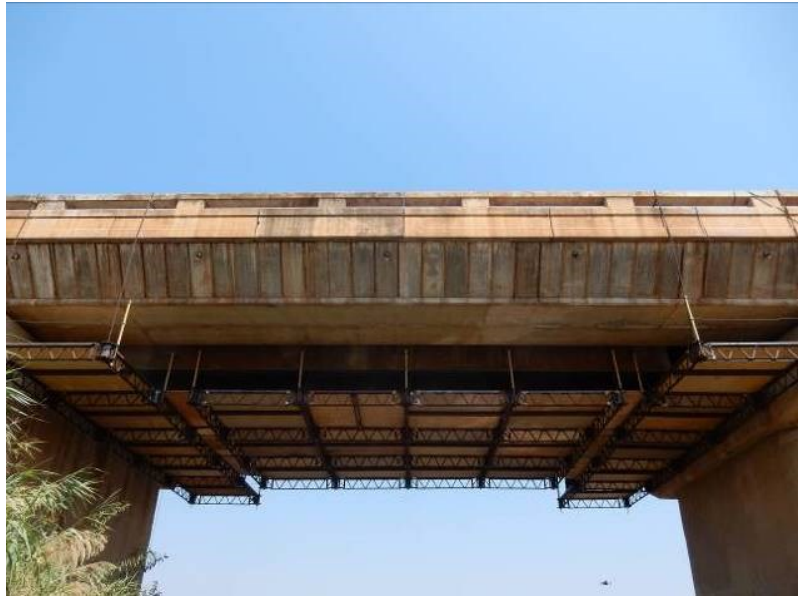

Fig 17: Temporary platforms used on the Komati River Bridge B1604.

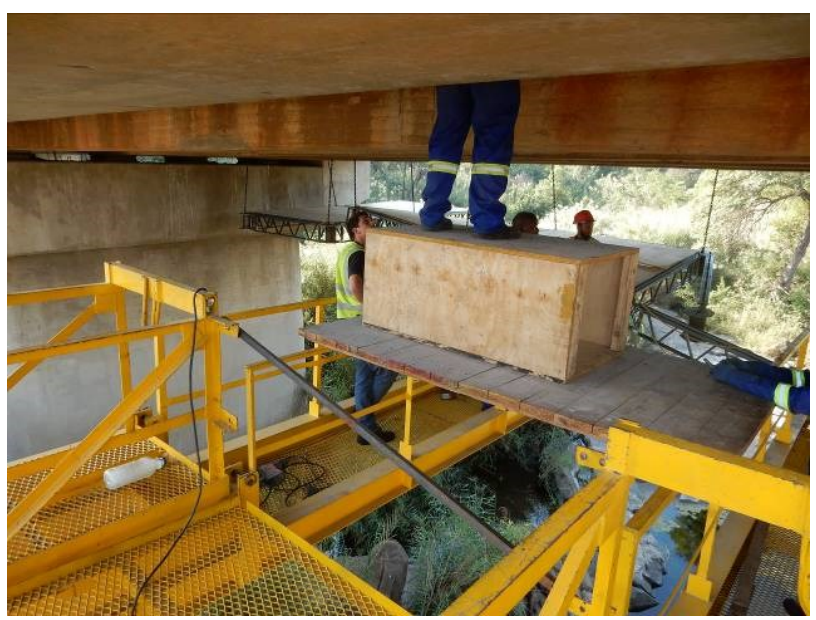

Fig 18: Mobile under bridge access unit/bogie. 
The access system cantilevered a maximum of $4.8 \mathrm{~m}$ and supported a maximum of $227 \mathrm{~kg}$ or two workers with tools. Additional bracing to resist wind loads was also installed. This same process was followed on all spans of the bridge. The workers utilised a pre-erected cat ladder as shown in Fig 19 to access the working platform from the top of the bridge.

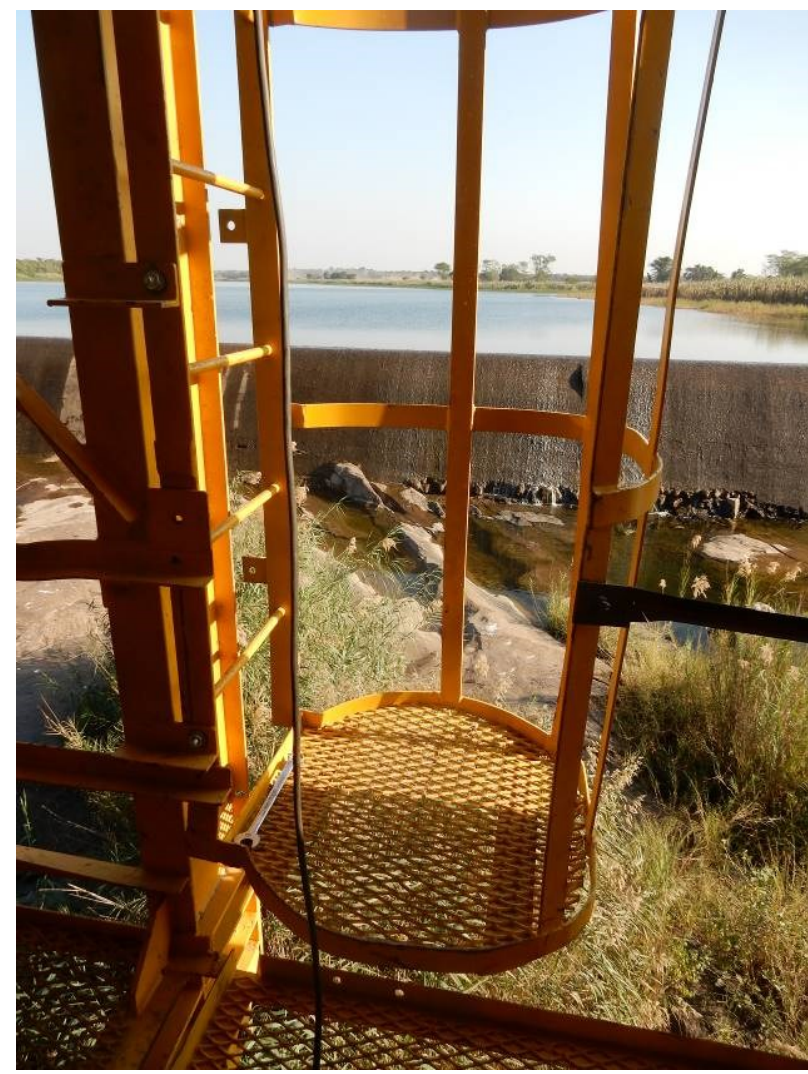

Fig 19: Cat ladder.

The access platforms were moved from span to span as and when required. The platforms were easily removed after the completion on of the rehabilitation works.

\subsection{Bridge Jacking}

Each span of the bridge had to be jacked to replace the old steel bearings. Jacking brackets were used at the abutments and piers. The brackets were secured by means of chemical anchors as shown in Fig 20 and Fig $21.250 \times 250 \times 20 \mathrm{~mm}$ jacking plates were placed on the soffit of the beams and levelled above the jacking contact point. Epoxy mortar was used on uneven surfaces.

Jacking at the one abutment was first done before moving to the first pier where jacking commenced from both sides of the pier. Measuring gauges were fitted and monitored to ensure equal lifting of the deck. Each jack had its own connection on the pump and its own pressure gauge with an individual valve to be able to control the lift of individual jacks.

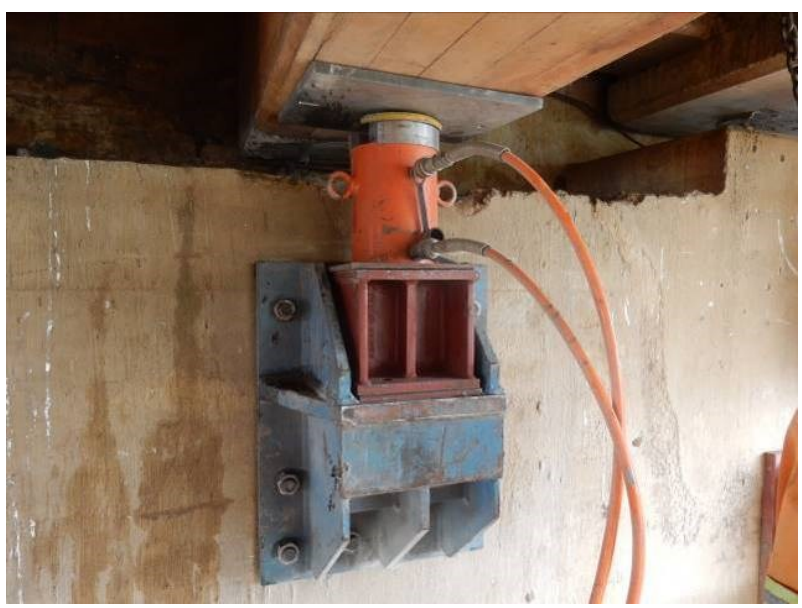

Fig 20: Jacking brackets.

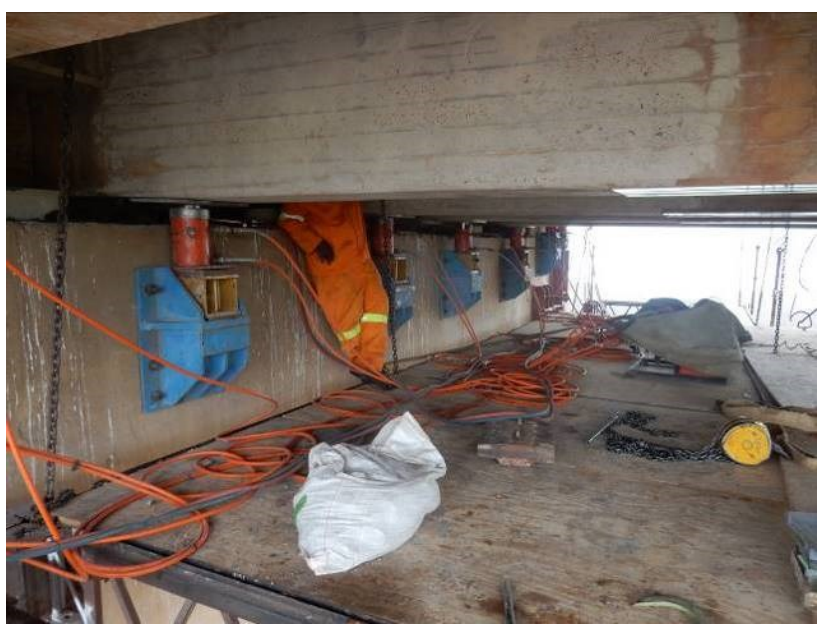

Fig 21: Jacking brackets with jacks installed.

All jacks were loaded to $75 \%$ of the dead load and locked. Theoretical dead loads were supplied by the design engineer at each jacking position. All connections and fittings were checked for any leaks. The lifting pressure was slowly increased in the sequence supplied by the design engineer and notes were taken of the pressure at which lift was observed.

Once the deck was free of load on the existing bearings, jacking was continued in increments of 5 to $10 \mathrm{~mm}$ to allow stability of the structure. Steel packers between the support and beams were installed as a failsafe system.

Once the bearings were in place the load could once again be taken up by the jacks and lowered onto the bearings in its final position. The concrete surface was repaired and jacking brackets and beams were moved to the next pier with all measuring guides and devices.

Special jacking brackets were used for piers 4, 7, 10 and 13 as these piers were hollow. The brackets for these piers were connected with stressing bars from both sides of the pier as shown in Fig. 22. 


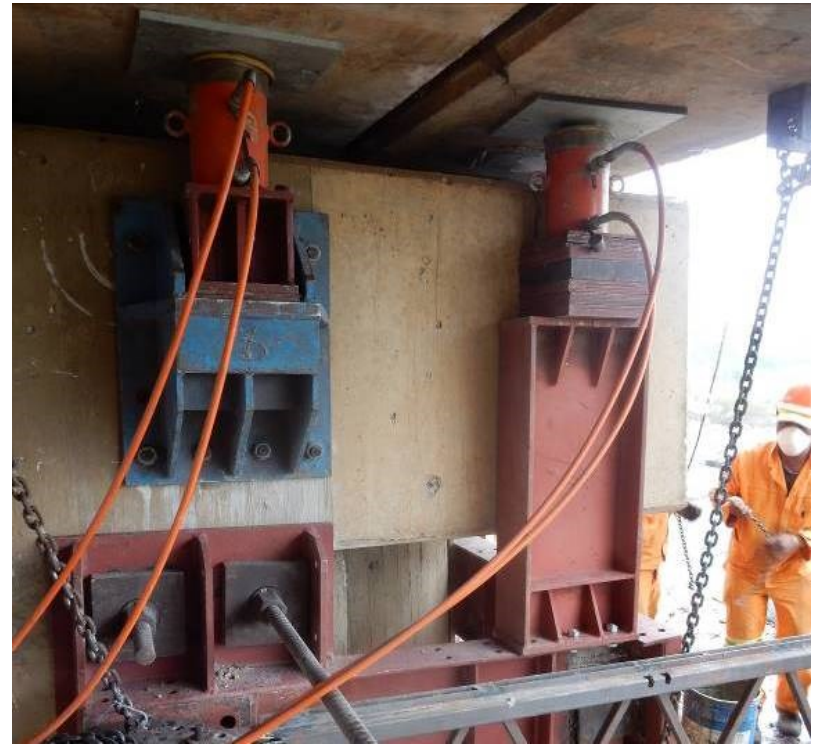

Fig 22: Jacking brackets used for special piers/hollow piers.

\section{Challenges and difficulties}

\subsection{Challenges encountered}

One of the key challenges during this project was the environment that the contractor had to work in and the requirement that the road over the bridge had to remain open during the rehabilitation process. In addition, crocodiles in the river posed an additional safety risk. A photo of a crocodile visitor is shown in Fig 23 next to the Bridge.

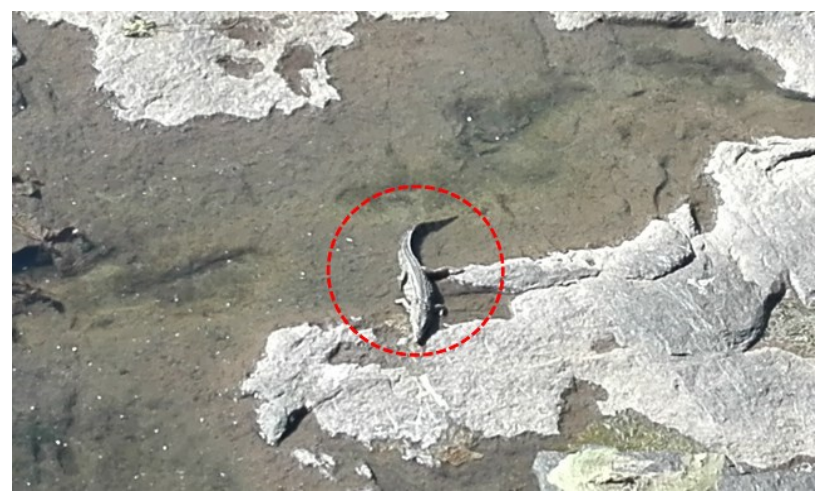

Fig 23: Crocodile next to the bridge (approximately 2.5 metres away).

Another challenge was to keep the workers hydrated during the extreme heat conditions during summer. During the rainy season, the contractor had to be cautious of the rising flood levels. Fig 24 shows the overflow of the upstream dam.

Traffic accommodation was an ongoing challenge throughout the duration of the project. Both shoulders of the road width were closed throughout the project. The contractor had to use this space for the mobile under bridge access units/ bogies shown in Fig 25.

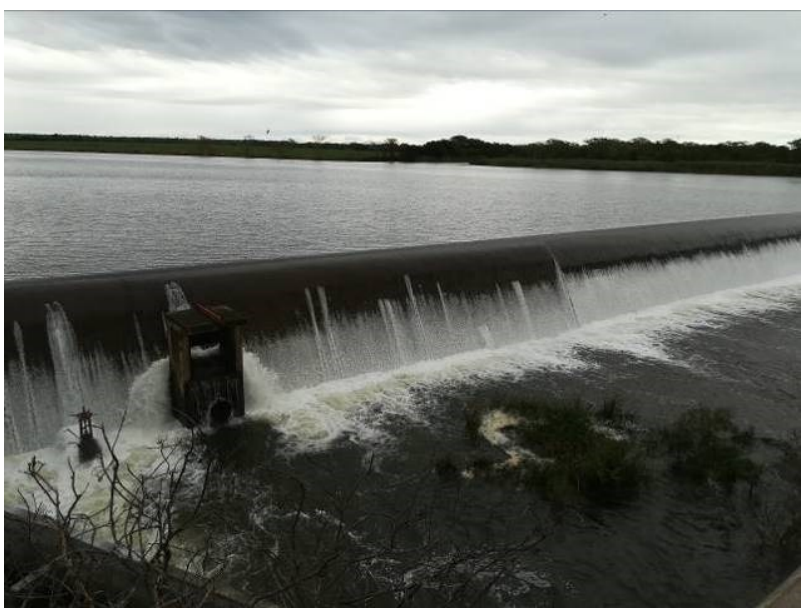

Fig 24: Flooding over the upstream dam's spill way.

Stop and go traffic accommodation intervals were also implemented during jacking of each individual span for replacing the bearings. These intervals had to be short to avoid traffic congestion. A large number of vehicles (especially heavy vehicles) crossed the bridge on a daily basis. The road was closed for short intervals (20min) and only during off-peak periods.

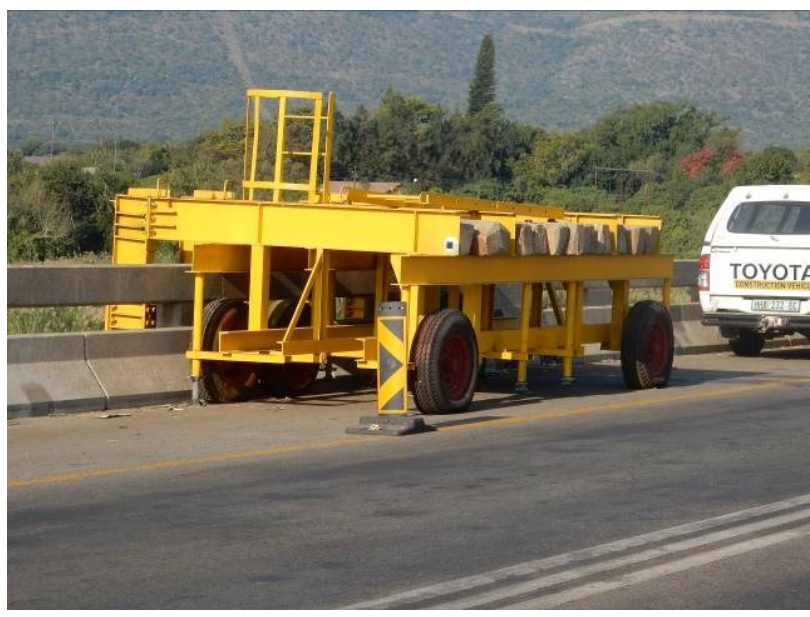

Fig 25: Mobile under bridge access unit.

\subsection{Contractual programme and dates}

All documents were compiled in terms of TRAC procedures in accordance with CIDB prescriptions.

The COLTO 1998 version of the Standard Specifications for Road and Bridge Works was implemented. TRAC has instructed that the SAICE Conditions of Contract for Construction Work, 1st Edition, 2004 as amended be applicable to this contract (not the 2010 edition).

The actual contract commencement date started in March 2017 and was completed in December 2017.

\section{Conclusion}

SMEC South Africa was appointed to undertake the detailed inspection, rehabilitation design and construction supervision of the Komati River Bridge, 
Bridge B1604. The bridge is situated on the N4 Section 8 at $\mathrm{km} 67.0$ and provides an important crossing point over the Komati River to the Lebombo Border post between South Africa and Mozambique. It was originally constructed in 1940 and subsequently widened in 1998.

A detailed inspection of the bridge was conducted using an UBIU after which the rehabilitation design was completed and tender documentation for the repair items on the bridge was compiled.

DSC Zendon cc successfully completed the rehabilitation works in 12 months, which included: (i) replacement of the steel bearings; (ii) external strengthening of the inner deck beams; (iii) replacement of the Thorma joints; (iv) crack injection and spalling repair of the beams; (v) protective coating on bridge elements.

Potential flooding, extreme weather conditions, crocodiles and difficult traffic accommodation were some of the challenges experienced throughout this project. 